\title{
Modifying the Properties of Concrete with Acrylic Acid using Pumice Aggregate as Partial Replacement of Coarse Aggregate
}

\author{
Agboola Shamsudeen Abdulazeez ${ }^{1}$, Musa Abdulhakeem Kolawole², \\ Ushie Gabriel $^{3}$, Tapgun Justin ${ }^{4}$, \\ ${ }_{1,2 \& 3}$ M.Tech Student, Abubakar Tafawa Balewa University Bauchi, Nigeria \\ ${ }^{4}$ College of Arts, Science and Technology Kurgwi, Shendam Plateau, Nigeria
}

\begin{abstract}
Over the years, the construction industry consumes large amount of materials and depletes natural resources in large amount, this practice depletes natural resources like aggregates and may cause problem of shortage in the nearest future. In order to attain sustainability, emphasis is made on circular pattern of consumption as against the linear pattern of consumption. Pumice Concrete Aggregate (PCA) is an example of naturally occurring aggregate material with highly vascular glassy rough textured rock from volcanic origin can be used as an aggregate substitute material. In addition efforts have also been made to eliminate the problem associated with cement used in the production of concrete which include early hydration, segregation and shrinkage nature of specimen so produced additive known as acrylic acid was introduced in the mix. The study was conducted through experimental research approach. Plain concrete were produced specimen using granite and compared with specimen produced using pumice aggregate and acrylic acid was introduced to the mix. Properties of aggregates, fresh and hardened concrete were obtained through experimentation and results were presented using table and graphs. The study established that at 28 days compressive strength of concrete with $0 \%$ admixture, slightly reduced in pumice aggregate concrete with $4.61 \%$ and $2.64 \%$ in self-cured and $\mathrm{H}_{2} \mathrm{O}$ environment respectively. Slump test for pumice aggregate reduced with increase aggregate replacement. Pumice aggregate had higher water absorption as compared to $5 \%$ for pumice aggregate and other replacement for both self-cured concrete and $\mathrm{H}_{2} \mathrm{O}$ environment. Pumice aggregate high water absorption ability resulted to a lower workability, low abrasion resistance as compared plain concrete although $5 \%$ replacement with pumice aggregate concrete has same abrasion value as that of plain concrete. Pumice aggregate has a lower specific gravity of 1.11 compared to 2.65 for coarse aggregate. Specific gravity affects density of concrete thus concrete produced with pumice aggregate is expected to reduce. The study concluded that the optimum aggregate replacement is 5\% but pumice aggregate can replace coarse aggregate up-to $10 \%$ and with the inclusion of acrylic acid the engineering properties of the concrete generally is improved.
\end{abstract}

Keywords: Pumice aggregate, Acrylic acid, Bulk density, Specific gravity, Slump Test, Compressive strength, Water absorption test, Abrasion resistance test, Self-curing.

\section{INTRODUCTION}

Concrete is one of the most widely used construction material in the world. It is a fundamental construction material used to fulfill the housing and infrastructural need of the society having the basic constituent of conventional fine and coarse aggregate, cement and water. It has proven to be a leading construction material for more than a century and it is estimated that the global production rate annually is at $1 \mathrm{~m} 3$ (approximately 2.5 ton) per capita [1]. Another way of developing enhancing properties in concrete is to introduce an additive such as acrylic acid in to the mixture. Many researchers utilized natural aggregates in the production of concrete but few researches have been carried out producing concrete using pumice concrete aggregate. However, with the quest for affordable housing for both the rural and urban population in developing countries, various proposals focusing on reducing the cost of conventional building material have been put forward. One of the suggestions in the forefront has been the sourcing, development and use of alternative, non-conventional local construction materials, additive and admixtures, including the possibility of using some agricultural wastes and residues as construction materials [2]. The problem of over dependence on conventional building materials can be solved by diverting our attention toward the local sourcing of alternative materials for building and construction. It was for this reason that the Nigerian Building and Road Research Institute (NBRRI) was established in 1978. NBRRI laid emphasis on the development of suitable local building materials from mineral deposits and agro industrial wastes that are in abundance at little cost [3]. Furthermore the rate of environmental degradation and deterioration can be reduced by diversifying materials and sources of aggregates for convectional aggregates extracted from quarrying and other materials for concrete production.

The construction industry is uniquely positioned to meet the challenges of sustainable development by reducing the quantity of aggregate and cement in concrete and by using alternate building materials. It is an established fact that fly ash, ground granulated blast furnace slag (GGBFS) can replace cement partially or completely, furthermore to not compromise the integrity of concrete samples and to improve the performance of concrete the application of ecofriendly admixtures can be introduced in concrete mix. It is established that acrylic acid, effective microorganisms, Polyethylene Glycal (PEG), synthetic resin and Chlorinated Rubber could enhance the properties of concrete. Similarly other forms of aggregate can replace conventional aggregates with some modifications [4]. However pumice aggregate could also serve as a light weight concrete aggregate in the production of concrete product to replace conventional coarse aggregate. 
In the earlier time, problems were faced in the used of concrete such as workability, earlier strengths and the later strengths of concrete. A lot of research works have been carried out in order to overcome such problems such as porous nature of concrete, early hydration of concrete and segregation in concrete mix and as such the technology of concrete need improvement. Strength is also important because it is related to several other important properties that are more difficult to measure directly, and a simple strength test can give an indication of these properties [5]. Although concrete produced is assumed be strong and durable.

These days concrete is being used for wide varieties of purposes in different conditions. In these conditions ordinary concrete may fail to exhibit the required quality performance or durability. In such cases, admixture is used to modify the properties of ordinary concrete so as to make it more suitable for any situation [6]. An admixture is defined as a material, other than cement, water and aggregates that is used as an ingredient of concrete and is added to the batch immediately before or during mixing [6]. Producers used admixtures primarily to reduce the cost of concrete construction, to modify the properties of hardened concrete, to ensure the quality of concrete during mixing, transporting, placing and curing and to overcome certain emergencies during concrete operations. One of the many different admixtures is the acrylic acid which is a self-curing admixture. It is economic, environmental-friendly, sustainable. Self-curing or internal curing is a technique that can be used to provide additional moisture in concrete for more effective hydration of cement and reduced self-desiccation [7]. Acrylic acid is an organic compound with the formula $\mathrm{CH} 2=\mathrm{CHCOOH}$. It is the simplest unsaturated carboxylic acid, consisting of a vinyl group connected directly to a carboxylic acid terminus. This colorless liquid has a characteristic acrid or tart smell. Acrylic acid is chemical base on membrane forming compound they seals the concrete effectively. Self-curing concrete is one of the special concretes in mitigating insufficient curing due to human negligence paucity of water in arid areas, inaccessibility of structures in difficult terrains and in areas where the presence of fluorides in water will badly affect the characteristics of concrete [8]. The application of the concept of internal curing by means of saturated lightweight aggregate was applied and shown to be effective in eliminating autogenous shrinkage [9]. Secondly, Internal sealing; some chemicals serve as water retaining admixtures which aid in the production of self-curing concretes, such as Acrylic acid, Polyethylene Glycal (PEG), synthetic resin and Chlorinated Rubber which reduce the evaporation of water from surface of concrete and also help retention. The chemicals should have abilities to reduce evaporation from solution and to improve water retention in ordinary Portland cement matrix. [10]. this research explores the use of pumice aggregate and acrylic acid in the production of concrete samples. However the research aimed at modifying the properties of concrete with acrylic acid using pumice aggregate as partial replacement of coarse aggregate.

\section{MATERIALS AND METHODS}

All the materials used for laboratory experiment were procured from the immediate environment. The relevant standards were used in the process of conducting the experiments.

Materials: The materials for this study included, coarse aggregate fine aggregate, Cement, pumice aggregate, acrylic acid and water. Pumice was gotten from kasuwar kurmi in Kano state, Nigeria, and crushed with hammer to determine the size of the coarse aggregate needed for this work. It was soaked in water for 48 hours after which it was air dried for an hour under shed. The coarse aggregate was obtained from a quarry site within Bauchi metropolis. The fine aggregate was obtained from Bayara River-flow in Bauchi state. The ordinary Portland cement is the brand of Dangote of Grade 42.5 which was procured from vendors within Bauchi metropolis.

Specific Gravity: In determining the specific gravity of aggregate a pycnometer (a vessel of 1 litre capacity with a metal conical screw top and a $5 \mathrm{~mm}$ diameter hole at it apex, giving a water tight connection), tray, scoop, drying cloth and weighing balance were used. The test procedure was carried out in accordance to [11]. The apparatus used during the test include density bottle and stopper, funnel, spatula and weighing balance.

Bulk Density: In determining the bulk density for pumice and conventional coarse aggregate a weighing balance, metal cylinder of $7 \mathrm{dm}^{3}$ capacity, scoop, straight edge, tamping rod of $16 \mathrm{~mm}$ diameter and a drying duster (towel) were used. The test was carried out according to [12].

Workability Tests of wet Concrete: Slump test was conducted using the relevant cone for measurements. The tests were conducted in accordance with [13].

Curing: The specimens were removed from mould and kept under ambient room temperature without and covered with polythene leather without immersion in water. No extra treatment or external water was applied to the specimen over required curing period of 7 days, 14 days and 28 days. However, the second batches of concrete specimens were placed in the curing tank $\left(\mathrm{H}_{2} \mathrm{O}\right)$ for the required period. After the required time span, tests were conducted on the hardened concrete.

Density Test: This was carried out prior to crushing of the concrete specimen. At the end of each curing period, the concrete specimens were weighed using an electric weighing machine balance. Density is calculated as mass of concrete specimen in $(\mathrm{kg})$ divided by volume of concrete cube $\left(\mathrm{m}^{3}\right)$ and expressed in $\mathrm{kg} / \mathrm{m}^{3}$.

Compressive Strength Test of concrete: The compressive strength test was conducted in accordance with [14]. The 1: 1.8: 2.3 mix ratios were adopted using a water cement ratio of 0.5 . The ratio of pumice was that of coarse aggregate and acrylic acid was that of percentage of cement. The cubes were cast and cured for 7 days, 14 days and 28 days respectively. For each mix, 3 cubes were crushed to obtain the average strength of the concrete samples. The compressive strength is the ratio of the weight of cube and the cross sectional area.

Water absorption capacity test: This test was conducted at 28 days curing age for both self-curing and those cured in normal $\mathrm{H}_{2} \mathrm{O}$ environment for specimen containing $0 \%, 5 \%$, $10 \%$ and $15 \% \mathrm{PA}$ in accordance with [15]. A total of 20 specimens were tested for absorption capacity and for each 
of the test, three cubes each were placed in the electric oven to dry the specimens at $105^{\circ} \mathrm{C}$ for 24 hours. The specimens were removed from the oven and allowed to cool at room temperature before determining the initial weight which was recorded as (W1). The final weight was determined after the concrete specimen has been immersed in water for $24 \mathrm{hrs}$. It was removed and dried with a piece of cloth; re- weighed and recorded its weight as (W2). The equation 1 was used to compute the absorption capacity for the specimens.

Water absorption capacity $=\frac{\mathrm{W} 2-\mathrm{W} 1}{\mathrm{~W} 2} X 100-$ - (1)

Abrasion resistance test: Abrasion resistance is used to measure the resistance of concrete to surface wear by abrasion. It is aimed at determining the abrasion resistance of a material through sliding or scraping, thus causing a wearing down by friction. [16] Explained that abrasion value should not be more than $30 \%$ for wearing surface and $50 \%$ for other surfaces. A total of 20 specimens were tested after at 28 days of curing. Three (3) cubes each for self-curing and those cured in normal $\mathrm{H}_{2} \mathrm{O}$ environment, containing $0 \%, 5 \%$, $10 \%$ and $15 \%$ respectively were tested for abrasion resistance. On the day of testing, the initial weight of each concrete sample was determined before brushing and recorded as $\mathrm{W} 1$, after which a weight of $3.5 \mathrm{~kg}$ was mounted and tightly fixed to the wire brush. It was then used to brush the surface of concrete specimen 60 times and the specimen was then re- weighed while the value was recorded as W2. The relation used to determine abrasion resistance of the concrete sample is given in equation 2.

Abrasion resistance $=\frac{\mathrm{w} 1-\mathrm{W} 2}{\mathrm{~W} 1} \times 100 \ldots \ldots$ - - - (2)

\section{RESULTS AND DISCUSSION}

Figure 1 shows the slump values for plain and pumice aggregate concrete containing $0 \%, 0.5 \%, 1.0 \%, 1.5 \%$ admixture. Test indicates the pumice concrete had slump range between $10 \mathrm{~mm}$ and $30 \mathrm{~mm}$, while plain concrete has slump between 25 and $30 \mathrm{~mm}$ for concrete with conventional aggregate and pumice aggregate in addition with those concrete with admixture inclusion. The test result indicated that the concrete is of low and medium degree workability. The slump values decrease with increase pumice aggregate content however with the inclusion of admixture there was increase in the slump values of $5 \%$ pumice aggregate content which has same value with that of plain concrete. Figure 2 7 shows the density of the concrete specimen at 7 days, 14 days and 28 days curing. Density values decrease with increase pumice aggregate content, also the density of concrete specimen is increased with increase acrylic acid content; however increase above $1.5 \%$ acrylic acid result to decrease in density of the concrete specimen. This is anticipated to as the specific gravity and bulk density of the aggregate replacing material as shown in table 1 . In addition sample with $5 \%$ record optimum replacement content as it indicated the highest values, also $1.5 \%$ admixture content shows optimum addition level of admixture while $2.0 \%$ admixture content shows reduction in density and $15 \%$ replacement of coarse aggregate with pumice aggregate record low density. Fig 8 - 13 shows the compressive strength of concrete for self-cured and curing in $\mathrm{H}_{2} \mathrm{O}$ sample at hydration period of 7 days 14 days and 28 days. The compressive strength of all sample types decreased with increased pumice aggregate content as compared to plain concrete but with $5 \%$ pumice aggregate content the result shows optimum compressive strength for aggregate replacement. Furthermore there is increase in compressive strength with inclusion of admixture, but above $1.5 \%$ addition the strength began to decrease. However there is increase in compressive strength as the curing age is increased. In general is can be concluded that additive improved and enhanced the property of concrete at $1.5 \%$ addition, while $5 \%$ replacement of aggregate with pumice aggregate shows optimum aggregate replacement, and $0 \%$ percentage inclusion of pumice aggregate shows increased strength above all other aggregate replacement. Self-cured sample at 7 days shows that $0 \%$ addition of pumice increase the strength with addition of admixture up-to $1.5 \%$ but above $1.5 \%$ there is decrease in strength of the concrete specimen, in addition the strength index shows same strength level with $0 \%$ pumice with $1.5 \%$ acrylic acid. Also at 14 days selfcuring $5 \%$ addition of pumice shows optimum strength but there is drop in strength index of concrete at $15 \%$ replacement of pumice aggregate. At 28 days self-curing there is increase in strength of concrete up-to $10 \%$ replacement of conventional aggregate with pumice aggregate and the strength shows maximum increase at $1.5 \%$ admixture inclusion. While the curing in normal $\mathrm{H}_{2} \mathrm{O}$ environment, the result indicated that specimen cured in water $\left(\mathrm{H}_{2} \mathrm{O}\right)$ has significant increase in the strength index than the self-cured concrete. At 7 days curing the result shows that $5 \%$ replacement of aggregate has optimum strength compared to other pumice replacement addition. At 14 days curing age the result indicated that $0 \%$ replacement shows increased strength than other replacement level but maximum strength was indicated at $1.5 \%$ admixture inclusion. At 28 days curing age the maximum strength was observed at $0 \%$ replacement level of pumice aggregate, but $5 \%$ pumice addition with $1.5 \%$ admixture shows optimum strength. However admixtures enhance and improve significantly the strength of concrete. Figure 14 and 15 shows the result for water absorption at 28 days for selfcuring and concrete cured in normal $\mathrm{H}_{2} \mathrm{O}$ environment, the result indicated that $0 \%$ pumice replacement absorb lesser water than all other aggregate replacement in concrete, while aggregate replacement of 5\% shows less absorption of water in concrete than other aggregate replacement, in addition with $1.5 \%$ acrylic acid the result shows reduction in absorption capacity at all replacement level of coarse aggregate. Furthermore concrete specimen cured at $\mathrm{H}_{2} \mathrm{O}$ environment shows reduction is water absorption; the result indicated that $0 \%$ replacement of pumice at show less absorptivity, also $5 \%$ pumice replacement indicated optimum replacement for aggregate replacement. In general admixture addition at $1.5 \%$ indicates reduced absorption of water. Figure 16 present result of abrasion resistance test at 28 days for self-curing concrete specimen, $0 \%$ pumice addition shows more resistance to abrasion than other aggregate replacement, also $1.5 \%$ acrylic acid to control concrete shows more resistance to abrasion, in addition 5\% pumice aggregate replacement shows more resistance to abrasion at $1.5 \%$ acrylic acid addition. Figure 17 present results for 
abrasion resistance of concrete specimen cured in $\mathrm{H}_{2} \mathrm{O}$ at 28 days, the result shows that $0 \%$ pumice aggregate replacement at $1.5 \%$ acrylic acid addition shows more resistance to abrasion, while $5 \%$ pumice aggregate at $1.5 \%$ acrylic acid addition shows more resistance to abrasion than other aggregate replacement level. In general 5\% shows optimum percentage of pumice aggregate replacement, also acrylic acid showed improve performance at $1.5 \%$ addition.

However 5\% pumice replacement of coarse aggregate shows significant increase in strength index as compared to other higher aggregate replacement, also $0.5 \%$ and $1.0 \%$ admixture shows enhanced properties of concrete specimen. Unlike $15 \%$ pumice aggregate replacement and $2.0 \%$ acrylic acid addition which shows no significant changes in strength of concrete specimen.

Table 1: Properties of materials

\begin{tabular}{ccc}
\hline Material Uncompacted Compacted & Mean \\
Bulk & Bulk & Specific \\
density & density & gravity \\
\hline Fine aggregate & 1257 & 1475 \\
2.53 & \\
Coarse aggregate 1437 & 1538 \\
2.65 &
\end{tabular}

$\begin{array}{lll}\text { Pumice aggregate } & 584 & 628\end{array}$
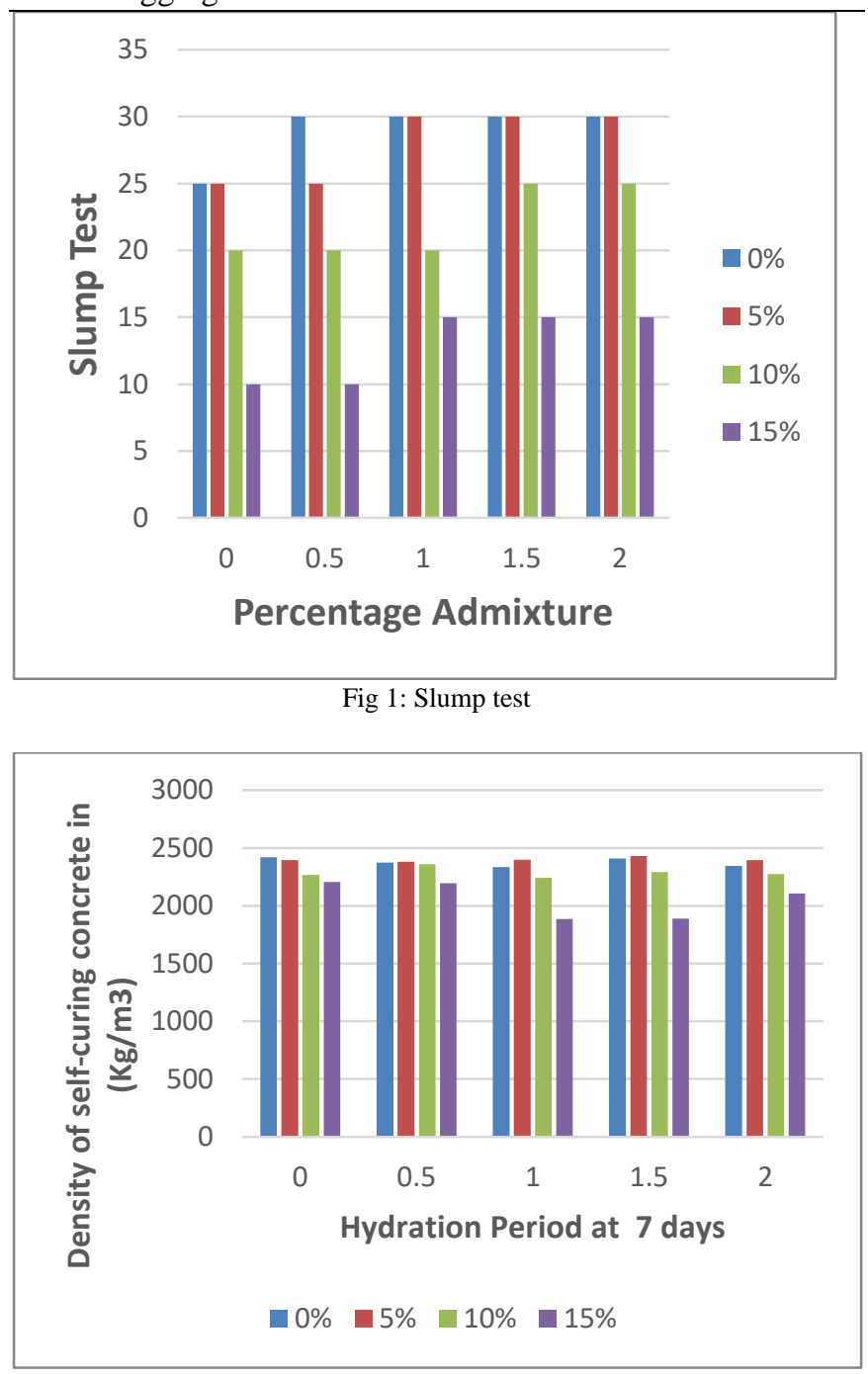

Fig 2: Density of self-cured concrete at 7 days

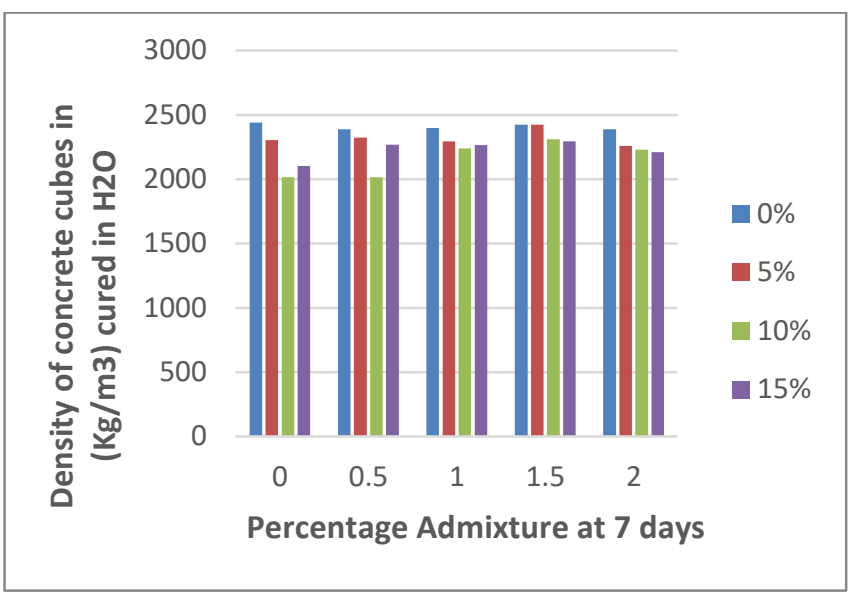

Fig 3: Density of concrete cured in $\mathrm{H}_{2} \mathrm{O}$ at 7 days

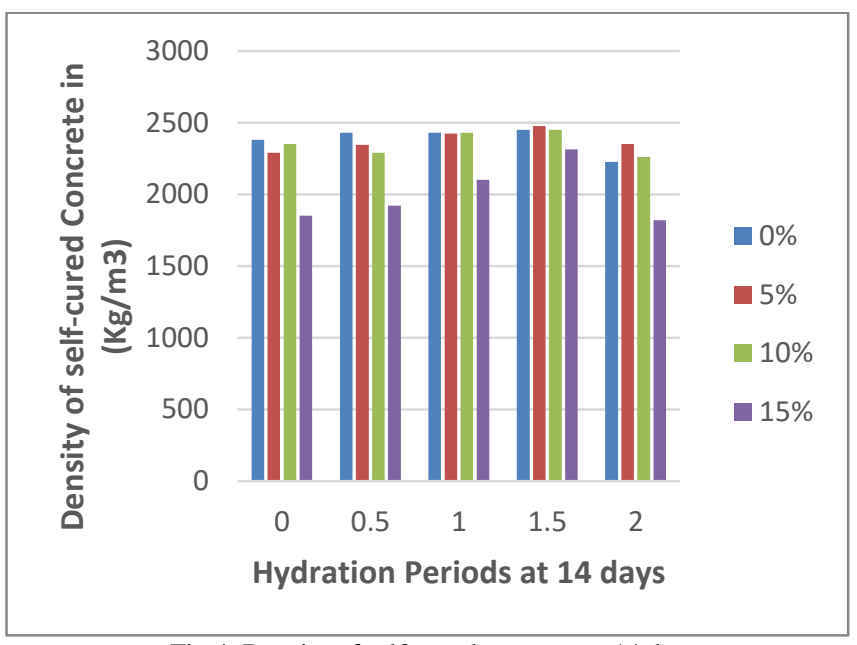

Fig 4: Density of self-cured concrete at 14 days

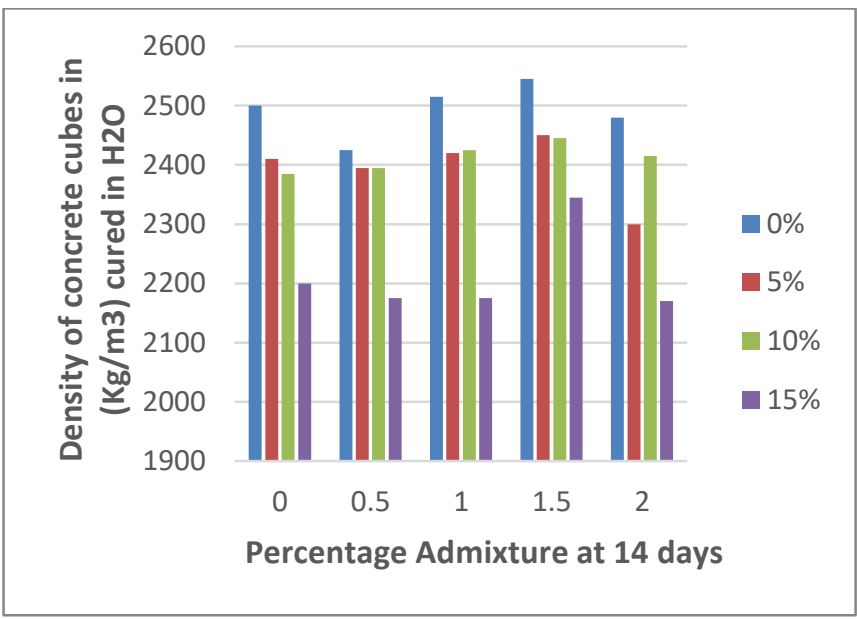

Fig 5: Density of concrete cured in $\mathrm{H}_{2} \mathrm{O}$ at 14 days 


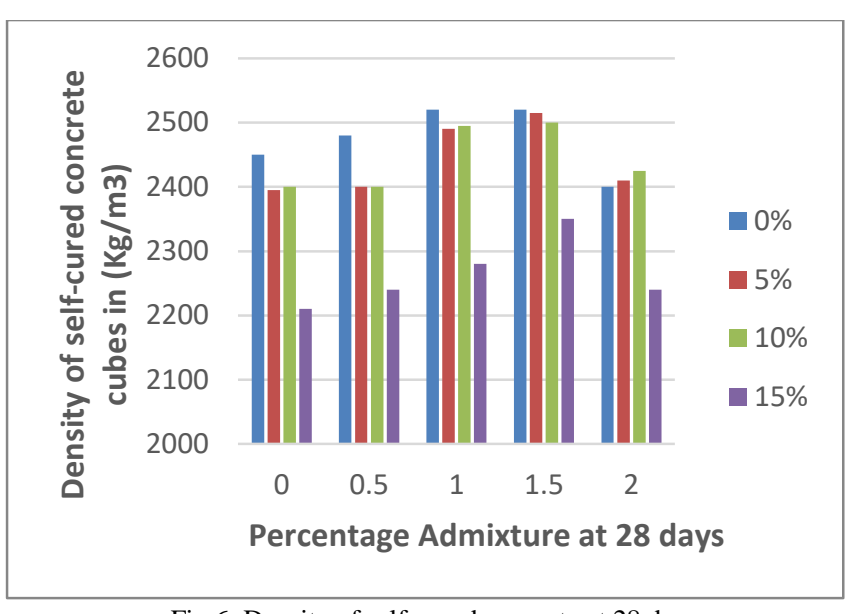

Fig 6: Density of self-cured concrete at 28 days
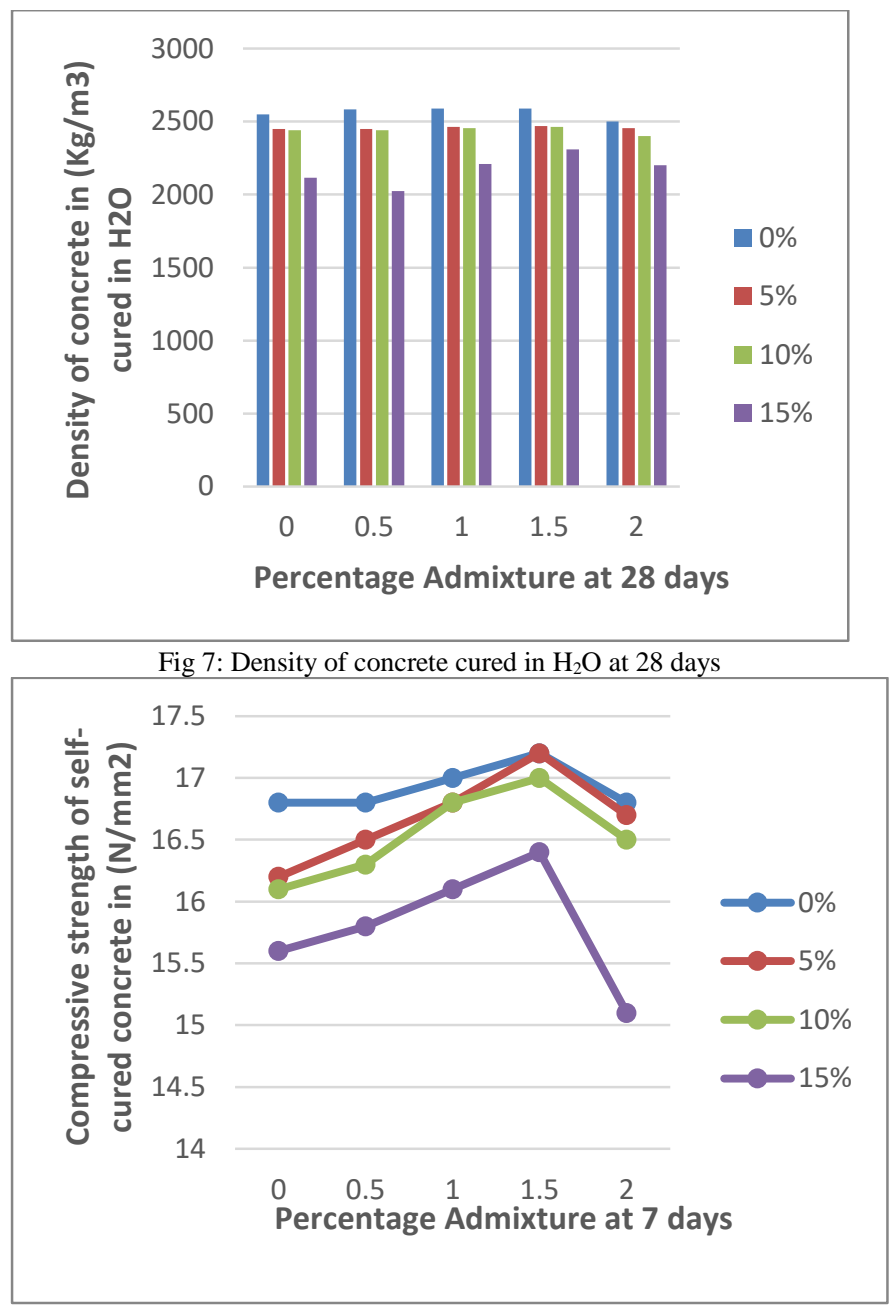

Fig 8: Compressive strength of self-cured concrete at 7 days

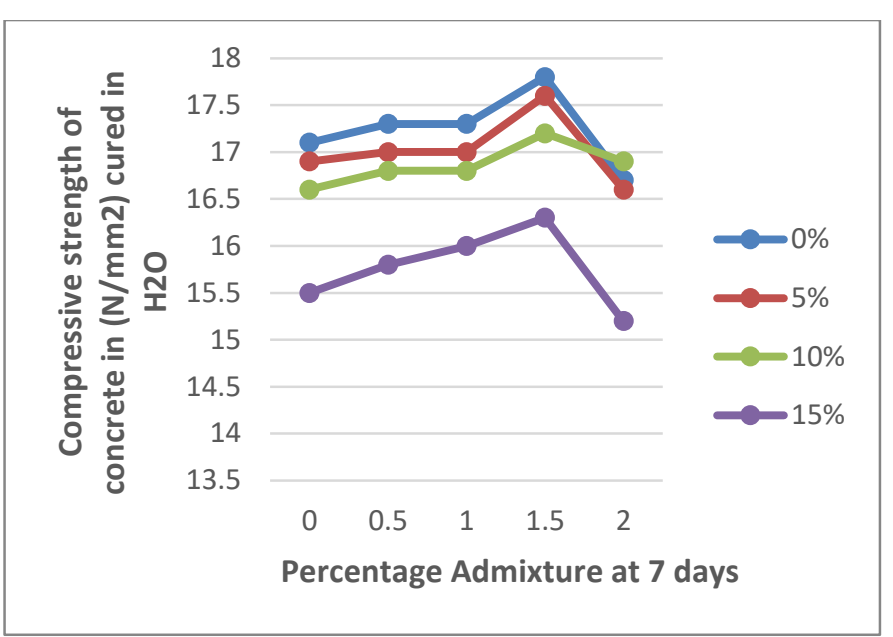

Fig 9: Compressive strength of concrete cured in $\mathrm{H}_{2} \mathrm{O}$ at 7 days

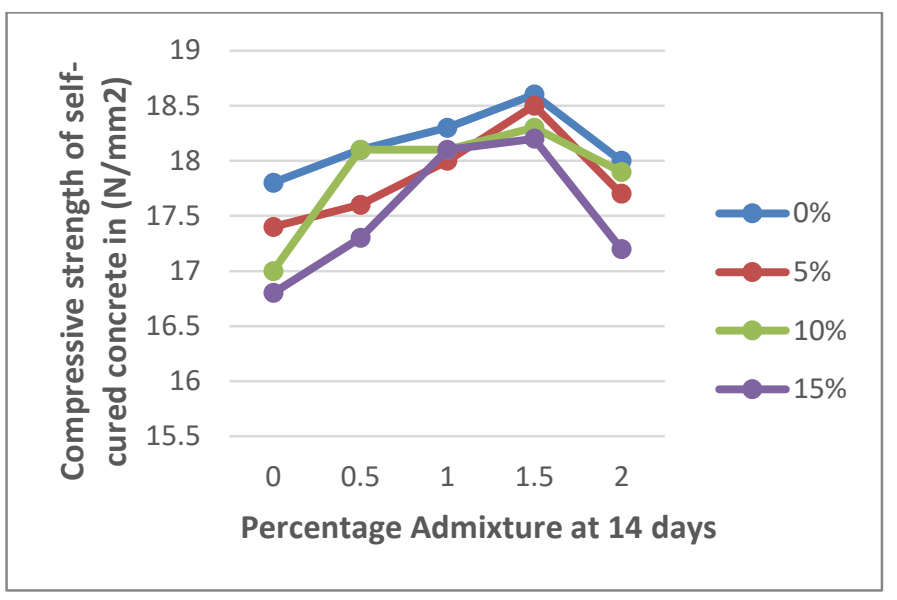

Fig 10: Compressive strength of self-cured concrete at 14 days

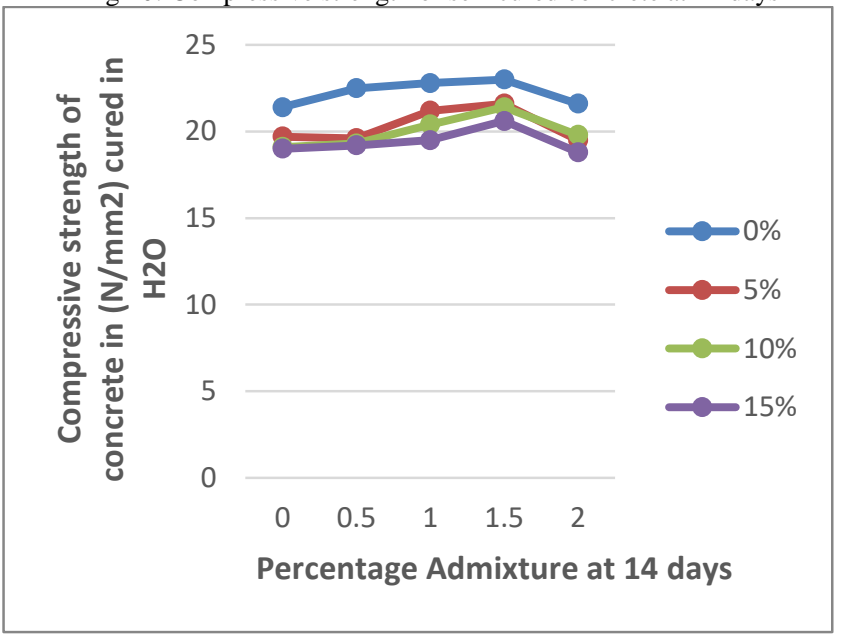

Fig 11: Compressive strength of concrete cured in $\mathrm{H}_{2} \mathrm{O}$ at 14 days 


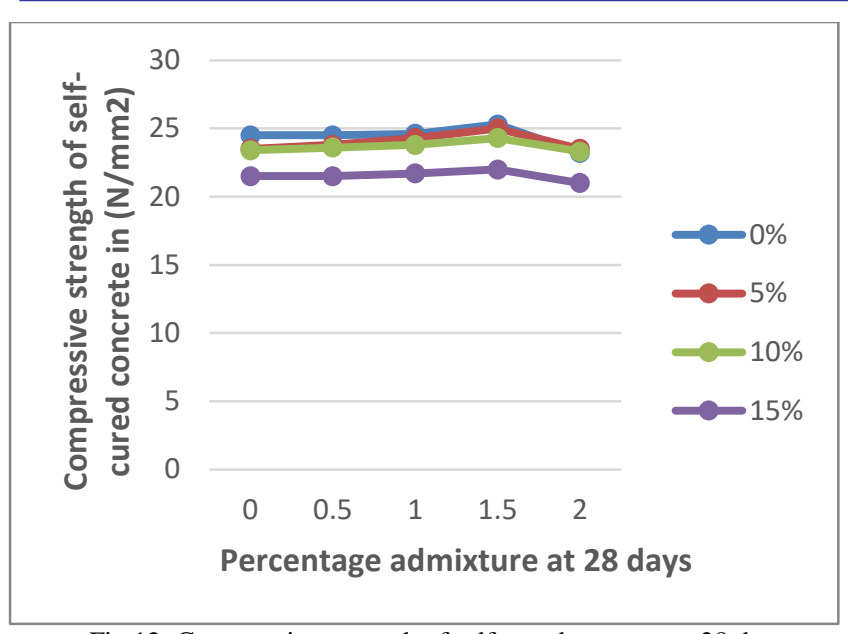

Fig 12: Compressive strength of self-cured concrete at 28 days

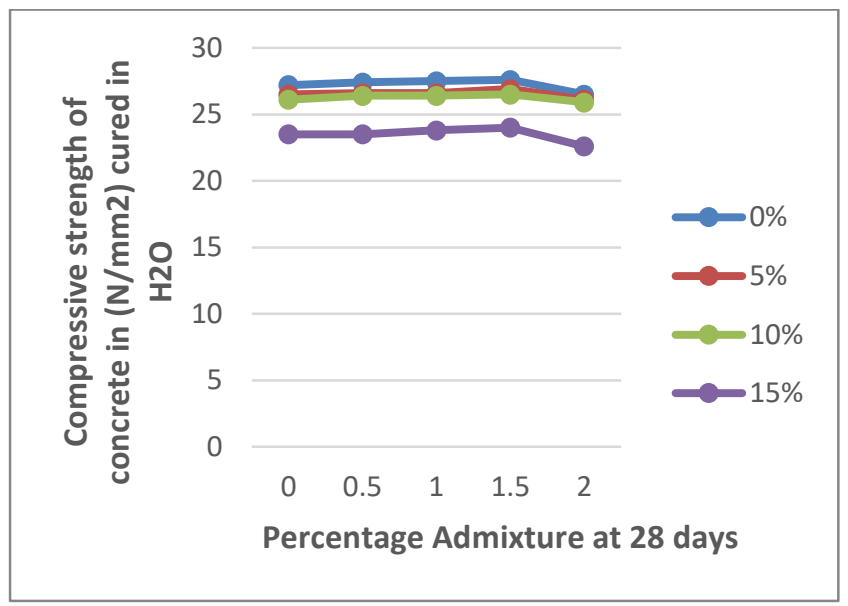

Fig 13: Compressive strength of concrete cured in $\mathrm{H}_{2} \mathrm{O}$ at 28 days

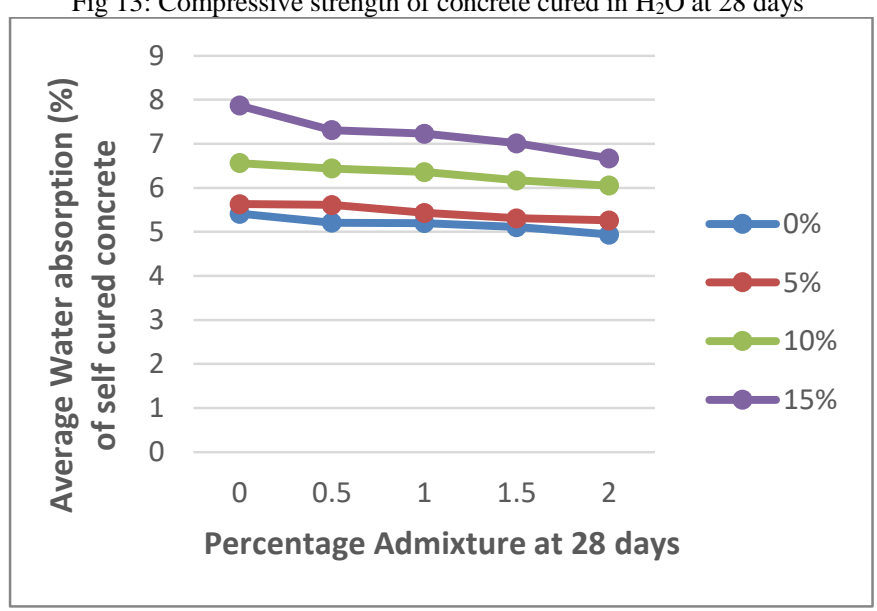

Fig 14: Water absorption test of self-cured concrete at 28 days

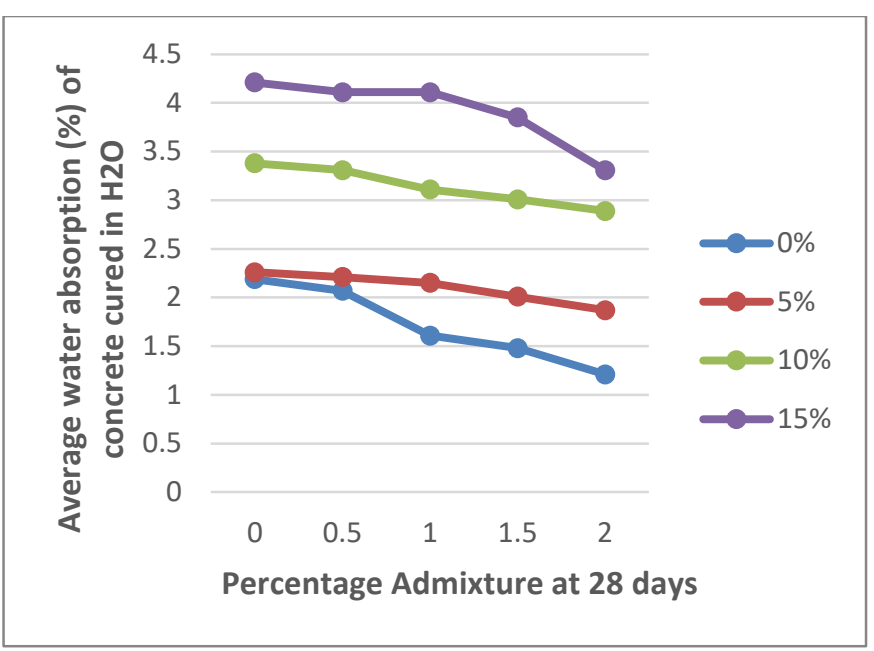

Fig 15: Water absorption test of concrete cured in $\mathrm{H}_{2} \mathrm{O}$ at 28 days

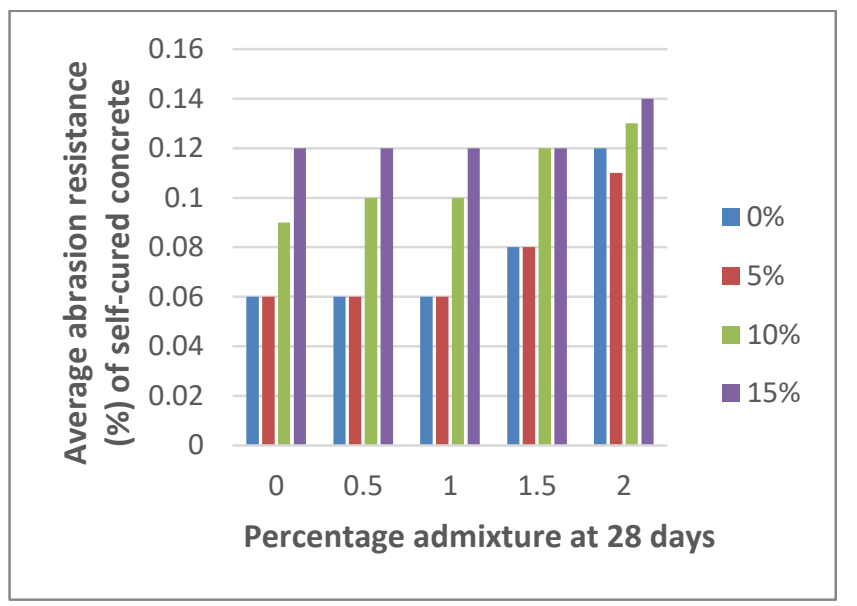

Fig 16: Water absorption test of concrete cured in $\mathrm{H}_{2} \mathrm{O}$ at 28 days

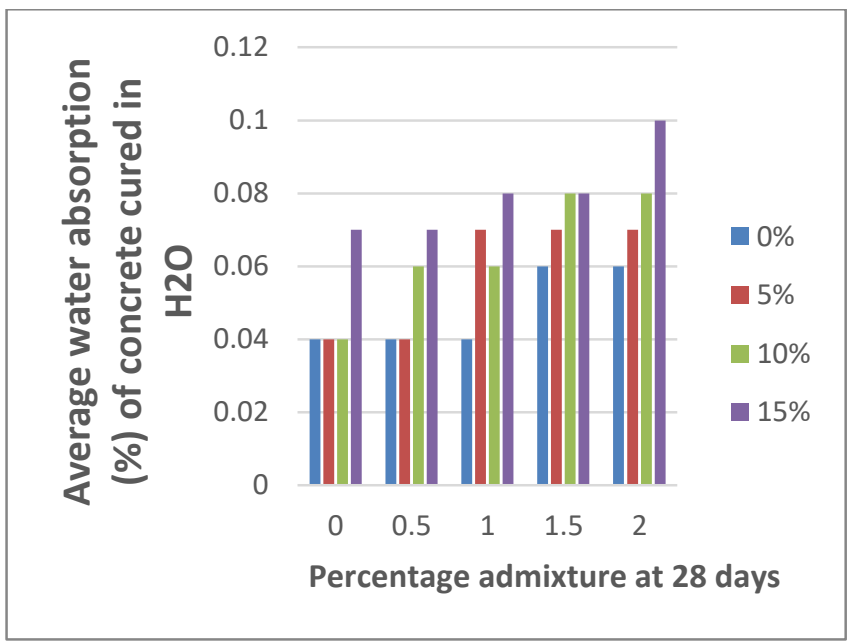

Fig 17: Water absorption test of concrete cured in $\mathrm{H}_{2} \mathrm{O}$ at 28 days

\section{CONCLUSION}

The pumice aggregate was used to replace coarse aggregate at $5 \%-15 \%$ in ratios while admixture was added in ratios of $0.5 \%-2.0 \%$. The workability of the fresh mixes fell within the low and medium classifications. The Compressive strengths was maximum at $0 \%$ aggregate replacement at strength declined at above $10 \%$ replacement level of aggregate at 28 days curing which indicates that $5 \%$ and $10 \%$ 
replacement levels meet the requirement of BS EN 206-1: 2000 for class C25/30 and C20/25 respectively for heavy weight concreting and LC25/28 and LC20/22 respectively for light weight concreting. The study suggests that pumice aggregate could be replaced up-to $10 \%$ with optimum replacement level at 5\%. The density related values shows similar result with reduced density at 28 days at $15 \%$ aggregate replacement level. The research concluded that pumice aggregate can be used as aggregate material for concrete production and can produce very strong concrete but can be used up-to $15 \%$ for light weight concrete. Acrylic acid is also a good self-curing agent producing strong and workable concrete. Self-curing concrete provide better hydration that as the curing age is increased as compared to water cured concrete. The workability of concrete increases as the quantity of acrylic acid is increased. Self-curing also provide solutions to many problem faced by concrete due to lack of proper curing. Further study are recommended using a different mix and altering water cement ratio, and also strength properties using different sizes of pumice aggregate also is also recommended.

\section{REFERENCES}

[1] Neville, A. M. (2003). Properties of Concrete (4th Ed.). Harlow, England: Prentice Hall.

[2] Kulkarni P. P., Chavan P. G., Pagar C. B., (2016). Coconut Shell As Coarse Aggregate In Concrete International conference on recent Trends in Engineering and Science.

[3] Ukot, U (1989) Building materials research activities at NBRRI. Ten years of building and road research act.

[4] Radhakrishna., Praveen K., Venugopal K., Vinod S., (2015), Characteristics of Alternative building materials.
International Conference on Food Nutrition and Civil Engineering Dubai (UAE)

[5] Peter, D. and John, I. (2010). Construction Materials - Their nature and behavior. New York, USA: Spon Press

[6] Shetty, M. S. (2005). Concrete Technology; Theory and Practice, S Chad and Company, New Delhi, pp. 124-238.

[7] Joseph B.M (2016), Studies on proportion of Concrete Using Poly Ethylene Glycol. IOSR Journal of Mechanical and Civil Engineering, 12-17.

[8] Jagannadha-Kumar M.V., M. Srikanth K. JagannadhaRao, (2012) "Strength characteristics of self-curing concrete" IJRET: International Journal of Research in Engineering and Technology Volume: 01, Issue: 01, Sept, Available @ http://www.ijret.org

[9] Zhutovsky, S., Kovler, K., and Bentur, A. (2002). Efficiency of Lightweight Aggregate for Internal Curing of High Strength Concrete to Eliminate Autogenous Shrinkage. Materials and Structures, Vol. 35, p.97-101

[10] Dahyebhai P.M. and Pitroda J.R. (2014). Introducing Self-curing Concrete in Construction Industry. International Journal of Engineering Research \& Technology (IJERT), 3, 1286-1289.

[11] British Standard 1377 part 2 (1970). Methods of determination Specific gravity of aggregate. BSI Publication British Standard Institution, London.

[12] British Standard 812 part 2 (1995).Testing aggregate part 2.Methods of determination of bulk density. BSI Publication British Standard Institution, London.

[13] British Standard, (1983). Testing concrete; Method for determination of slump. BS 1881-102, BSI, Linfordwood, Milton Keynes MK14 6LE, U.K

[14] British Standards Institution 1970. BS 1881, Part, Methods of Testing Concrete Strength, BSI London.

[15] British Standard, (1983). Testing concrete; Method for determination of water absorption. BS 1881-122, BSI, Linfordwood, Milton Keynes MK14 6LE, U.K.

[16] Gupta, B. L. and Gupta A. (2012). Concrete technology, Published by A. K. Jain. For Standard Publishers Distributors. 1705-B, NaiSarak, Delhi-110006. 